\title{
Simultaneous brightness contrast as a function of perceptual set
}

\author{
MICHAEL PARRISH AND KENDON SMITH \\ UNIVERSITY OF NORTH CAROLINA AT GREENSBORO ${ }^{1}$
}

Using the method of constant stimuli, degree of simultaneous brightness contrast was determined for $17 \mathrm{Ss}$ within the context of one of Hering's standard demonstrations. Of these Ss, 8 were given a "whole-perceiving" and 9 an "analytical" perceptual set. The analytical $S$ s showed a significantly smaller contrast effect $(p=.02$, two-tailed test).

Berman \& Liebowitz (1965) have documented the contemporary resurgence of interest in Ewald Hering's concepts of retinal function. Three recent volumes (Hurvich \& Jameson, 1964; Ratliff, 1965; Hurvich \& Jameson, 1966) also testify to this resurgence.

In their own paper, Berman \& Liebowitz (1965) are concerned particularly with the phenomenon of simultaneous brightness contrast and, more specifically, with the question of whether or not a simple, retinal explanation will account for that phenomenon. Their empirical findings lead them to conclude that it will not: "..... simultaneous contrast is not a simple function of luminance and spatial variables... ..additional concepts are needed to fully explain subjective contrast....." (Berman \& Liebowitz, 1965, p. 256). The present paper is in agreement with Berman and Liebowitz, and it reports data which support theirs.

The experimental technique used by Berman and Liebowitz depended upon the division of the visual field by fine lines. It was presumed that the local, retinal effects of these lines were negligible, and thus that their real effects arose from their establishment of visual contours (Berman \& Liebowitz, 1965, pp. 255-256). The effects of the lines were in fact in the direction of enhanced contrast. It is always possible, however, to question their actual negligibility from the standpoint of retinal dynamics.

It occurred to us that it might be possible to enhance or diminish simultaneous brightness contrast in the complete absence of any manipulation of the visual field. In analogue with Benussi's (1904; cf., Woodworth \& Schlosberg, 1954, p. 421) work with the Muller-Lyer illusion, and in extension of Riedel's earlier suggestions (Riedel, 1937; cf., Woodworth \& Schlosberg, 1954, p. 451), our study investigated the effect of $E$ 's instructions (and thus presumably of S's perceptual set) upon simultaneous brightness contrast.

Method

The original Ss were 20 graduate students and upperclassmen in psychology, 12 being male and eight female. They were assorted randomly into two groups of 10 members apiece, the "whole-perceiving" ("W") group and the "analytical" ("A") group.

As he participated in the experiment, an $S$ from either group was seated at one end of a long table, his head in a padded head-holder. At the other end of the table (distance, $164 \mathrm{~cm}$ ), in $S^{\prime} s$ frontal plane, stood a framed wooden panel of outside dimensions $64 \times 35 \mathrm{~cm}$. The left half of the panel was occupied by a sheet of gray construction paper of one reflectance, the right half by a second such sheet of differing reflectance. A circular aperture, $5.3 \mathrm{~cm}$ in diameter, appeared in each sheet, centered $17.5 \mathrm{~cm}$ from the base of the panel and $7.5 \mathrm{~cm}$ from its vertical centerline. Behind each aperture, and behind a concentric $8-\mathrm{cm}$ aperture in the panel, a rotating wheel permitted the presentation of a range of samples of gray paper. The entire arrangement was suggested by one of Hering's well-known demonstrations (Hurvich \& Jameson, 1964, p. 124).

The gray papers used in the study were obtained from the Color-aid Company, 116 East 27th Street, New York, New York. This firm produces a "white," a darkening series numbered " 1 " through " 8, " and a "black" paper. In terms of relative amounts of "black" and "white," as mixed by color-wheel, paper no. 1 has a judged reflectance of $61.0 \%$ and paper no. 8 has a judged reflectance of $2.0 \%$; these two papers were used as the two large inducing fields in the present study. Paper no. 4 (19.5\%) was used as the standard sample, appearing always behind the lighter inducing field. Papers no. 4 (19.5\%), 5 (14.0\%), 6 (8.5\%), $7(5.5 \%)$, and $8(2.0 \%)$, appearing always behind the darker inducing field, served as comparison samples.

A screen of taut "curtain-sheer" cloth (69 threads per in.) stood in S's frontal plane, $5 \mathrm{~cm}$ before his eyes; it was intended to provide the diffusing effect generally found to enhance simultaneous contrast. In front of the screen and just below S's field of vision stood a $60-\mathrm{w}$ light in a hemispherical metal reflector. The light was generally off, and the room dark; the light was activated by Hunter timer for just $3 \mathrm{sec}$. for each of S's trials.

In his first experimental session, each $\mathrm{S}$ was essentially instructed in the method of constant stimuli. Specifically, his directions were to judge each comparison sample, as it was presented behind the darker field, as lighter or darker than the standard sample, which appeared behind the lighter field. The sole difference between the treatment of an $S$ from group $W$ and one from group $\mathrm{A}$ lay in the fact that a member 
of group W was told:

As you make each judgment, you are to take a "whole-perceiving" attitude. That is, you are to view the perceptual field up here as a whole; then you are to give me your judgment about the piece of paper behind the dark sheet, based on this "over-all" look at the situation. This will be similar to a "general-impression" sort of judgment.

But a member of group A was told instead:

Pay attention to the pieces of paper behind the large sheets and try to analyze them in comparison to each other. Do not be concerned with the front sheets; in fact, do the best you can to ignore them. You are making judgments about the lightness and darkness of the pieces of paper behind the large front sheets.

For each $\mathrm{S}$, the initial placement of the inducing fields was determined at random. With this initial placement, S was given 10 trials (in random order), two with each comparison sample. He was then given three additional such sets of 10 trials. The inducing fields were shifted, over all four sets of trials, in an a $b$ b a sequence; the room remained dark as the fields were being exchanged. The 40 judgments involved in the whole session required about $20 \mathrm{~min}$.

Each $S$ was tested over four such sessions, no more than one session falling on any single day. The initial position of the inducing fields for any session after the first one was simply the opposite of that of the previous session. Instructions were repeated at the beginning of every session, and a reminder of the point of view to be taken was given after every 10 judgments.

By advance decision, data from the first session were discarded in the final analysis. Each $S$ thus generated 120 useful judgments. All 120 judgments had been made with the standard sample appearing behind the lighter field and the comparison sample behind the darker field. There were 24 judgments for each of the five comparison samples; half of the judgments for each sample had been made with the inducing fields in one relationship, and half with those fields in the other relationship.

\section{Results and Discussion}

A psychometric function was drawn for each $\mathrm{S}$, and the point of subjective equality (PSE) determined by exact linear interpolation. Ten PSEs were thus found within each group. The results from two Ss in group W and one $\mathrm{S}$ in group $\mathrm{A}$ were, however, omitted in statistical analysis. ${ }^{2}$ Careful post-experimental questioning elicited the information that, contrary to the Es'expectation that $S$ would fixate alternately upon the samples to be compared, these three Ss had made a practice of fixating away from the samples. The remaining $17 \mathrm{Ss}$ had conformed to expectation, and it seemed wisest to confine analysis to their results only.

Doing so, it was found that the mean PSE in group W was a reflectance of $5.84 \%$, and that that in group $A$ was one of $10.21 \%$. Inasmuch as the original assignment of reflectances to the comparison samples had depended upon judgmental matching, not too much importance could be attached to these mean figures or, certainly, to the individual values which underlay them. There was, however, no ambiguity about the order in which the magnitudes of the reflectances of the comparison samples fell, and thus none about the order of the magnitudes of the respective Ss' PSEs. It was accordingly possible and appropriate to compare the two groups in terms of the Mann-Whitney $U$ test. When this was done, they were found to differ at the .02 level of significance (2-tailed test). It is of incidental interest that the same analysis performed upon all 20 scores originally obtained showed significance at the .01 level.

These results suggest strongly that, just as it is possible to alter the magnitude of the Muller-Lyer illusion by manipulating perceptual set (Benussi, 1904), so it is also possible to alter the degree of simultaneous brightness contrast. The effect, furthermore, does not seem to be trivial. We thus concur strongly in the conclusions of Berman \& Liebowitz (1965), as cited at the outset of the present paper.

\section{References}

Benussi, V. Zur Psychologie des Gestalterfassens. In A. Meinong Untersuchungen zur Gegenstandstheorie und Psychologie. Leipzig: Barth, 1904

Berman, P. W., \& Liebowitz, H. W. Some effects of contour on simultaneous brightness contrast. J. exp. Psychol., 1965, 69 251-256.

Hurvich, L. M., \& Jameson, D. Outlines of a theory of the light sense. Cambridge, Massachusetts: Harvard University Press, 1964. (Translation of: Hering, E. Grundzüge der Lehre vom Lichtsinn. Berlin: Springer, 1920.)

Hurvich, L. M., \& Jameson, D. The perception of brightness and darkness. Boston: Allyn \& Bacon, 1966.

Ratliff, F. Mach bands: Quantitative studies on neural networks in the retina. San Francisco: Holden-Day, 1965.

Riedel, G. Über die Abhängigkeit optischer Kontraste von Gestaltbedingungen. Neue psychologische Studien, 1937, 10, 1-44.

Woodworth, R. S., \& Schlosberg, H. Experimental psychology. New York: Holt, 1954

\section{Notes}

1. This paper is based upon research done for the Master's thesis by the first author (who is now at The Pennsylvania State University) under the direction of the second.

2. The individual PSEs in the two groups, in terms of percent reflectance, were as follows: Group W: 3.82 , (4.61), 4.86, 5.27, $5.55,5.81,(6.02), 6.47,6.58$, and 8.33 ; Group A: $4.16,7.38,7.52$, $(7.77), 7.77,8.33,10.16,14.66,15.72$, and 16.17 . Values in parentheses are the ones omitted in computations (see text). 